\title{
Wind Energy Conversion Systems Based On a DFIG Controlled By Indirect Vector Using PWM and SVM
}

\author{
Naim Cherfia, Djallel Kerdoun \\ Department of Electrical Engineering, LGEC-Research Laboratory, Algeria
}

\section{Article Info \\ Article history: \\ Received Apr 19, 2015 \\ Revised Nov 16, 2015 \\ Accepted Dec 10, 2015}

\section{Keyword:}

DFIG

PWM

SVM

Turbine

Wind

\begin{abstract}
This work presents consideration and use of the asynchronous generator in the production of wind energy. To do this, a model of the wind turbine has been established, the mathematical model of the doubly fed induction generator (DFIG) variable speed is presented and the control quantities used when integrated with a wind system. A modeling in a diphasic reference mark related to the stator field and a strategy vector control active and reactive power are offered with a PWM and SVM technique for inverter control is considered in our work.
\end{abstract}

\section{Corresponding Author:}

Naim Cherfia, Djallel Kerdoun

Department of Electrical Engineering,

LGEC-Research Laboratory,

Constantine 1 University, 25000 Constantine, Algeria.

Phone: +213780102155

Email: msn822009@live.fr, kerdjallel@yahoo.fr

\section{INTRODUCTION}

This paper is to study the indirect control power of doubly fed induction generator (DFIG) operation generator for this, our work is organized as follows:

- $\quad$ The first part is dedicated to the description and modeling of wind turbines based on physical equations responsive operation.

- $\quad$ The second part, we present a mathematical model of the (DFIG) will simulate the model in generator mode.

- The third is devoted to the study of the technique of indirect control power to realize the conversion DCAC inverter using two voltage levels with technical using the PWM controller (Pulse Width Modulation) and SVM (space vector modulation)

\section{MODEL OF THE TURBINE}

A wind turbine, commonly called wind is a device which transforms a part of the kinetic energy of wind into mechanical energy available on a shaft and then into electrical energy via a generator (DFIG) [1].

Mechanical power available on the shaft of a wind turbine is expressed as:

$$
P_{m}=\frac{P_{m}}{P_{m t}} P_{m t}=C_{p} \cdot P_{m t}=\frac{1}{2} C_{p}(\lambda) \rho \pi R^{2} V_{1}^{3}
$$




$$
\lambda=\frac{\Omega_{1} \mathrm{R}}{\mathrm{V}_{1}}
$$

$\Omega_{1}$ : Rotation speed before multiplier.

$\mathrm{R}$ : rotor radius $35.25 \mathrm{~m}$.

$\rho$ : air density, $1.225 \mathrm{~kg} \cdot \mathrm{m}^{-3}$.

$$
C_{p}=f(\lambda, \beta)=C_{1}\left(\frac{C_{1}}{\lambda_{i}}-C_{3} \beta-C_{4}\right) \exp \left(\frac{C_{5}}{\lambda_{i}}\right)+C_{6} \lambda
$$

With:

$\frac{1}{\lambda_{\mathrm{i}}}=\frac{1}{\lambda+0.08 \beta}-\frac{0.035}{\beta^{3}+1}$

$\mathrm{C}_{1}=0.5176 ; \mathrm{C}_{2}=116 ; \mathrm{C}_{3}=0.4 ; \mathrm{C}_{4}=5 ; \mathrm{C}_{5}=21 ; \mathrm{C}_{6}=0.0068$ [1], [2].

Characteristics of $C_{p}$ in terms of $\lambda$ for different values of the pitch angle are shown in Figure 1. The maximum value of $C_{p}\left(C_{p \max }=0.4353\right)$ is reached of $\beta=2^{\circ}$ and $\lambda=10.01$. This particular value of $\lambda$ is defined as the nominal value [1], [3].

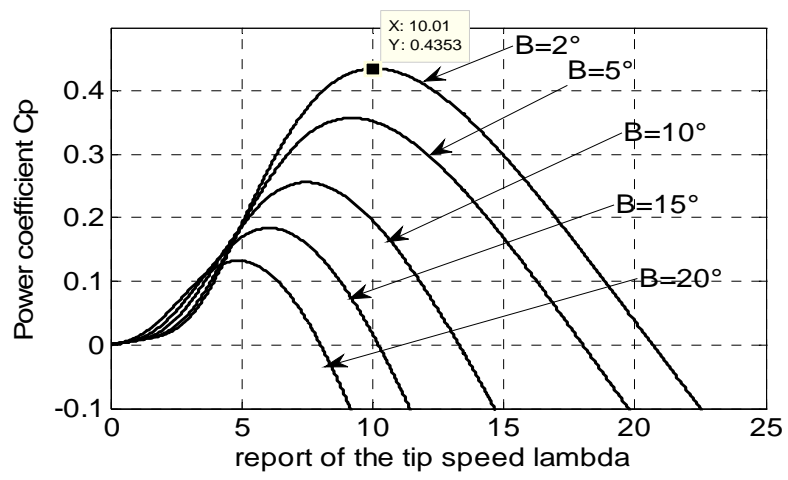

Figure 1. The power factor for different angles of stalls

\section{MODEL OF THE DOUBLY FED INDUCTION GENERATOR}

A commonly used model for the doubly fed induction generator (DFIG) is the Park model. The electrical equations of the DFIG in the Park reference frame are given as follows [4], [5]:

$$
\begin{array}{r}
\left\{\begin{array}{l}
\mathrm{v}_{s d}=\mathrm{R}_{\mathrm{s}} \mathrm{i}_{\mathrm{sd}}+\frac{\mathrm{d} \varphi_{s d}}{\mathrm{dt}}-\omega_{\mathrm{s}} \varphi_{\mathrm{sq}} \\
\mathrm{v}_{\mathrm{sq}}=\mathrm{R}_{\mathrm{s}} \mathrm{i}_{\mathrm{sq}}+\frac{\mathrm{d} \varphi_{\mathrm{sq}}}{\mathrm{dt}}+\omega_{\mathrm{s}} \varphi_{\mathrm{sd}}
\end{array}\right. \\
\left\{\begin{array}{l}
\mathrm{v}_{\mathrm{rd}}=\mathrm{R}_{\mathrm{r}} \mathrm{i}_{\mathrm{rd}}+\frac{\mathrm{d} \varphi_{\mathrm{rd}}}{\mathrm{dt}}-\omega_{\mathrm{r}} \varphi_{\mathrm{rq}} \\
\mathrm{v}_{\mathrm{rq}}=\mathrm{R}_{\mathrm{s}} \mathrm{i}_{\mathrm{rq}}+\frac{\mathrm{d} \varphi_{\mathrm{rq}}}{\mathrm{dt}}+\omega_{\mathrm{r}} \varphi_{\mathrm{rd}}
\end{array}\right.
\end{array}
$$

The stator and rotor flux are given as:

$$
\begin{gathered}
\left\{\begin{array}{l}
\varphi_{s d}=L_{s} i_{s d}+L_{m} i_{r d} \\
\varphi_{s q}=L_{s} i_{s q}+L_{m} i_{r q}
\end{array}\right. \\
\left\{\begin{array}{l}
\varphi_{r d}=L_{r} i_{r d}+L_{m} i_{s d} \\
\varphi_{r q}=L_{r} i_{r q}+L_{m} i_{s q}
\end{array}\right.
\end{gathered}
$$

In these equations, $R_{s}, R_{r}, L_{s}$ and $L_{r}$ are respectively the resistances and the inductances of the stator and the rotor windings, $\mathrm{L}_{\mathrm{m}}$ is the mutual inductance. 
$\mathrm{V}_{\mathrm{sd}}, \mathrm{V}_{\mathrm{sq}}, \mathrm{V}_{\mathrm{rd}}, \mathrm{V}_{\mathrm{rq}}, \mathrm{i}_{\mathrm{sd}}, \mathrm{i}_{\mathrm{sq}}, \mathrm{i}_{\mathrm{rd}}, \mathrm{i}_{\mathrm{rq}}, \varphi_{\mathrm{sd}}, \varphi_{\mathrm{sq}}, \varphi_{\mathrm{rd}}, \varphi_{\mathrm{rq}}$ are the $\mathrm{d}$ and $\mathrm{q}$ components of the stator and rotor voltages, currents and flux, whereas $\omega_{\mathrm{r}}$ is the rotor speed in electrical degree.

The electromagnetic torque is expressed as:

$$
C_{e m}=p\left(\varphi_{s d} \cdot i_{s q}-\varphi_{s q} \cdot i_{s d}\right)
$$

Stator and rotor variables are both referred to the stator reference Park frame. With the following orientation, the $\mathrm{d}$ component of the stator flux is equal to the total flux whereas the q component of the stator flux is null Figure 2. [6].

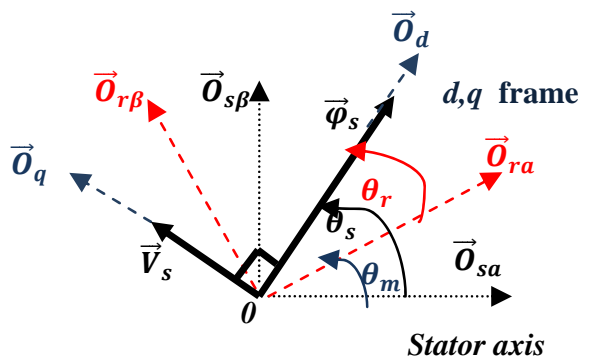

Figure 2. Determination of the electrical angles in Park reference frame

$$
\varphi_{\mathrm{sd}}=\varphi_{\mathrm{s}}, \varphi_{\mathrm{sq}}=0
$$

By replacing (9) in (6) and (8), the electromagnetic torque can be given as follows:

$$
\mathrm{C}_{\mathrm{em}}=-\mathrm{p} \frac{\mathrm{L}_{\mathrm{m}}}{\mathrm{L}_{\mathrm{s}}} \mathrm{i}_{\mathrm{rq}} \varphi_{\mathrm{sd}}
$$

Assuming that the resistance of the stator winding $\mathrm{R}_{\mathrm{s}}$ is neglected, and referring to the chosen reference frame, the voltage equations and the flux equations of the stator winding can be simplified in steady state as follows:

$$
\begin{gathered}
\left\{\begin{array}{c}
\mathrm{v}_{\mathrm{sd}}=0 \\
\mathrm{v}_{\mathrm{sq}}=\mathrm{v}_{\mathrm{s}}=\omega_{\mathrm{s}} \varphi_{\mathrm{s}}
\end{array}\right. \\
\left\{\begin{array}{c}
\varphi_{\mathrm{sd}}=\mathrm{L}_{\mathrm{s}} \mathrm{i}_{\mathrm{sd}}+\mathrm{L}_{\mathrm{m}} \mathrm{i}_{\mathrm{rd}} \\
0=\mathrm{L}_{\mathrm{s}} \mathrm{i}_{\mathrm{sq}}+\mathrm{L}_{\mathrm{m}} \mathrm{i}_{\mathrm{rq}}
\end{array}\right.
\end{gathered}
$$

From (12), the equations linking the stator currents to the rotor currents are deduced below:

$$
\left\{\begin{array}{c}
\mathrm{i}_{\mathrm{sd}}=\frac{\varphi_{\mathrm{s}}}{\mathrm{L}_{\mathrm{s}}}-\frac{\mathrm{L}_{\mathrm{m}}}{\mathrm{L}_{\mathrm{s}}} \mathrm{i}_{\mathrm{rd}} \\
\mathrm{i}_{\mathrm{sq}}=-\frac{\mathrm{L}_{\mathrm{m}}}{\mathrm{L}_{\mathrm{s}}} \mathrm{i}_{\mathrm{rq}}
\end{array}\right.
$$

The active and reactive powers at the stator side are defined as:

$$
\left\{\begin{array}{l}
P_{s}=v_{s d} i_{s d}+v_{s q} i_{s q} \\
Q_{s}=v_{s q} i_{s d}-v_{s d} i_{s q}
\end{array}\right.
$$
follows:

Taking into consideration the chosen reference frame, the above power equations can be written as

$$
\left\{\begin{array}{l}
P_{s}=v_{s} i_{s q} \\
Q_{s}=v_{s} i_{s d}
\end{array}\right.
$$


Replacing the stator currents by their expressions given in (15), the equations below are obtained:

$$
\left\{\begin{array}{c}
P_{s}=-v_{s} \frac{L_{m}}{L_{s}} i_{r q} \\
Q_{s}=\frac{v_{s} \varphi_{s}}{L_{s}}-\frac{v_{s} L_{m}}{L_{s}} i_{r d}
\end{array}\right.
$$

The block diagram of the DFIG model in Park reference frame is depicted in Figure 3, assuming a constant stator voltage $\left(\mathrm{v}_{\mathrm{s}}\right)$ [7].

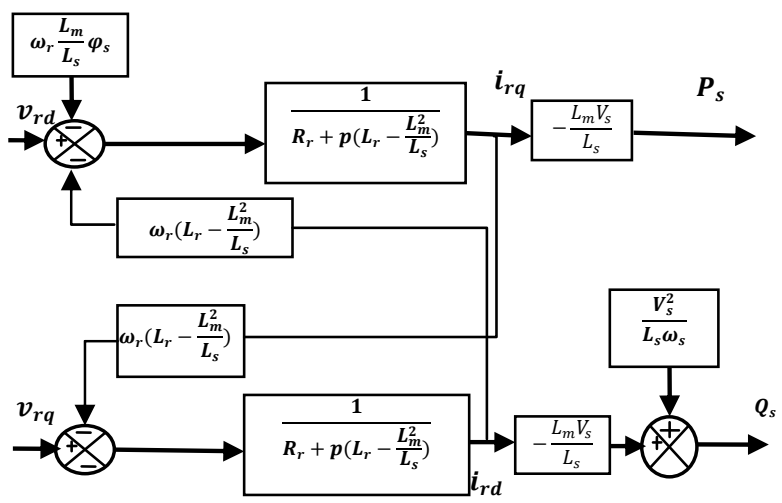

Figure 3. Block diagram of the DFIG model

\section{REGULATION WITH BUCKLE OF POWER}

to improve the control system the DFIG, we will introduce an additional loop control of active and reactive power in the block diagram of the control loop without power so that each axis controller contains two PI control, one to control the power and the other rotor current (figure 4) [8].

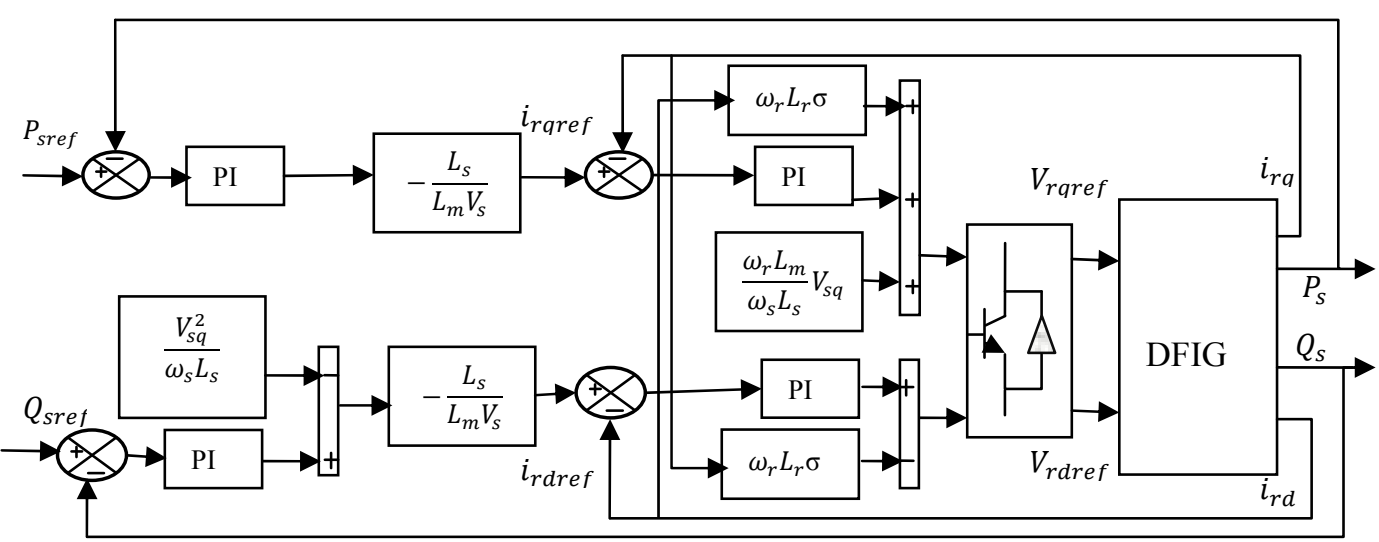

Figure 4. Schema block indirect regulation with loop power

\section{MODELLING OF VOLTAGE INVERTERS TWO LEVELS}

The three-phase voltage inverter at two levels, is composed of three independent arms, comprising two switches each. each switch comprises an IGBT or GTO thyristors and a diode connected in antiparallel. can be replaced group each transistor-diode switches by kj with $(j=1,2,3,4,5,6)$, we obtain the simplified diagram for each inverter as shown in Figure 5. [9]. 


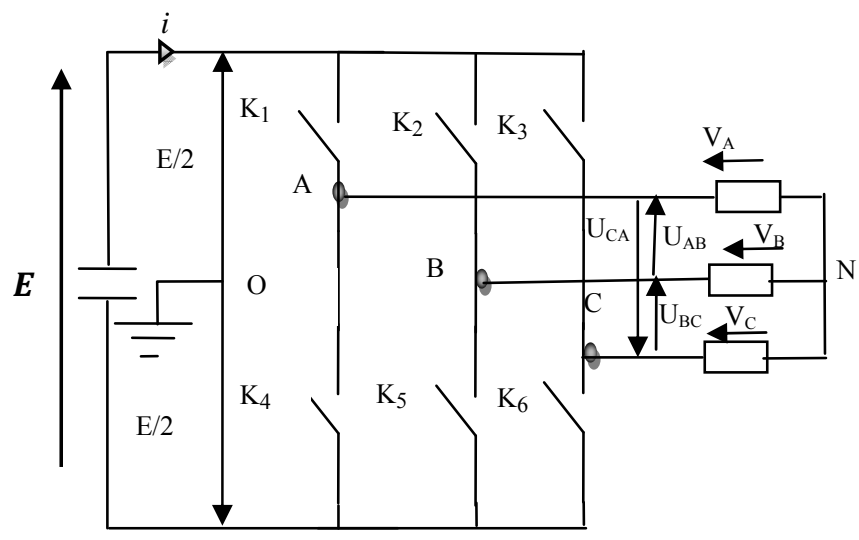

Figure 5. Simplified diagram of the three-phase inverter

The equations of simple voltage applied to the three phases are:

$$
\left\{\begin{array}{l}
\mathrm{V}_{\mathrm{A}}=\mathrm{V}_{\mathrm{AO}}+\mathrm{V}_{\mathrm{ON}} \\
\mathrm{V}_{\mathrm{B}}=\mathrm{V}_{\mathrm{BO}}+\mathrm{V}_{\mathrm{ON}} \\
\mathrm{V}_{\mathrm{C}}=\mathrm{V}_{\mathrm{CO}}+\mathrm{V}_{\mathrm{ON}}
\end{array}\right.
$$

Knowing that the system is symmetrical stator phase voltages:

so: $\quad V_{A}+V_{B}+V_{C}=0$

The voltage converter can be modeled by a matrix $[\mathrm{T}]$ providing passage $\mathrm{DC}$ to $\mathrm{AC}$.

$$
\left[\mathrm{V}_{\mathrm{AC}}\right]=[\mathrm{T}] .\left[\mathrm{V}_{\mathrm{dc}}\right]
$$

such that:

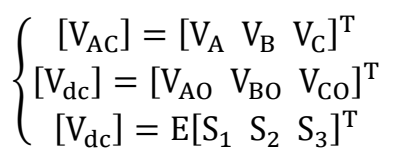

So, for each arm there are two independent states, these states can be considered as Boolean variables. Supposed ideal switching: $\mathrm{S}_{\mathrm{i}}=(1$ ou 0$)\{\mathrm{i}=1,2,3\}$.

The transfer matrix is:

$$
[\mathrm{T}]=\left[\begin{array}{ccc}
2 & -1 & -1 \\
-1 & 2 & -1 \\
-1 & -1 & 2
\end{array}\right]
$$

In our work, the switches of the inverter are made by using the PWM controller (Pulse Width Modulation) and SVM (space vector modulation).

\section{PULSE WIDTH MODULATION (PWM)}

The most widely used method of pulse width modulation is based carrier. this method is also known as the sinusoidal (SPWM), triangulation, subharmonic, or method suboscillation [10], [11]. Sinusoidal modulation is based on a triangular carrier signal as shown in Figure 6. In this method, three reference signals $\mathrm{U}_{\mathrm{AC}}, \mathrm{U}_{\mathrm{BC}}, \mathrm{U}_{\mathrm{CC}}$ comparing with triangular carrier signal $\mathrm{U}_{\mathrm{t}}$ which is common to all three phases. In this way, the logic signals $\mathrm{Sa}, \mathrm{Sb}, \mathrm{Sc}$ are generated, which define the switching times of the power transistors. 


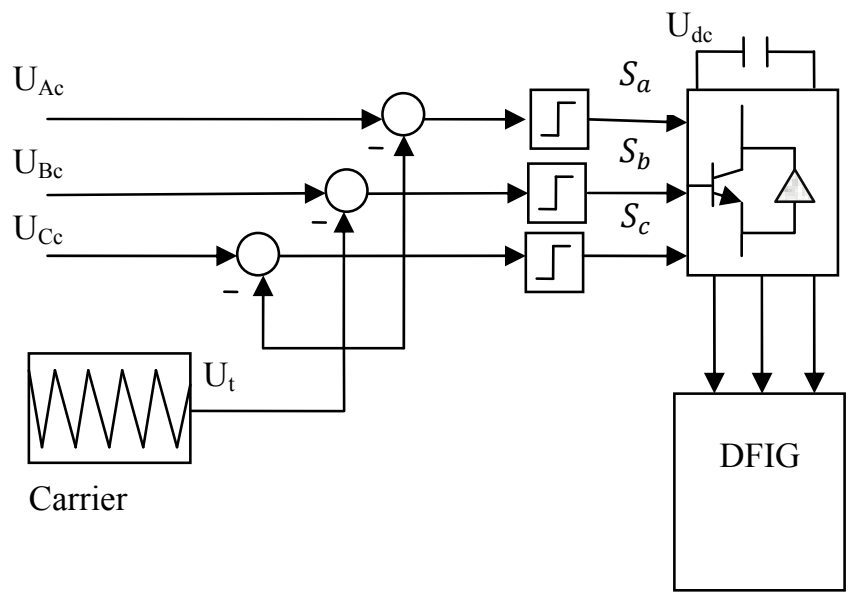

Figure 6. Block scheme of carrier based sinusoidal PWM

\section{THE SIMULATION RESULTS OF THE INDIRECT CONTROL WITH PWM}

The simulation is performed by imposing the active and reactive power reference $\left(\mathrm{P}_{\text {ref }}, \mathrm{Q}_{\mathrm{ref}}\right)$, while the DFIG is driven at variable speed Pref varies between -300000 and -1000000 watts and Qref varies between -100000 and -400000100000 VAR and de Isabc varies between $1000 \mathrm{~A}$ and $2500 \mathrm{~A}$

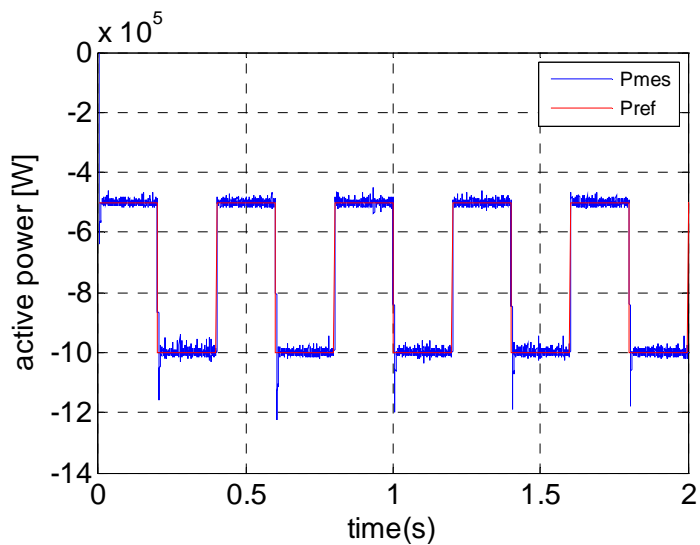

Figure 7. Electrical active power produced with PWM

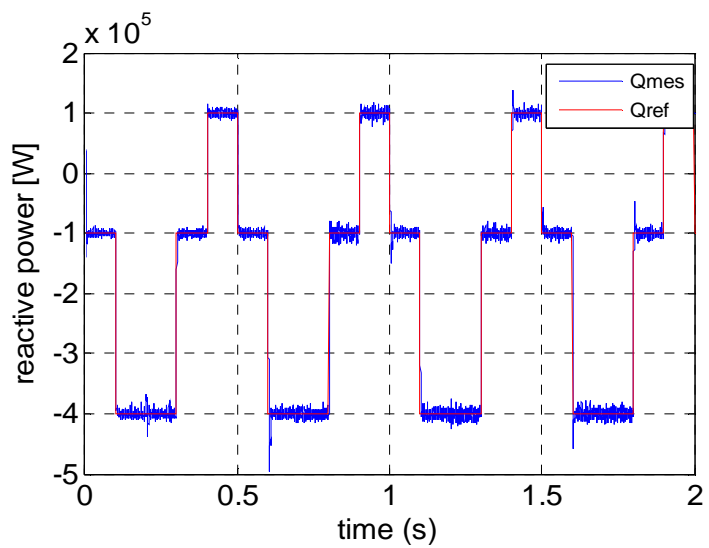

Figure 8. Electrical reactive power produced with PWM 


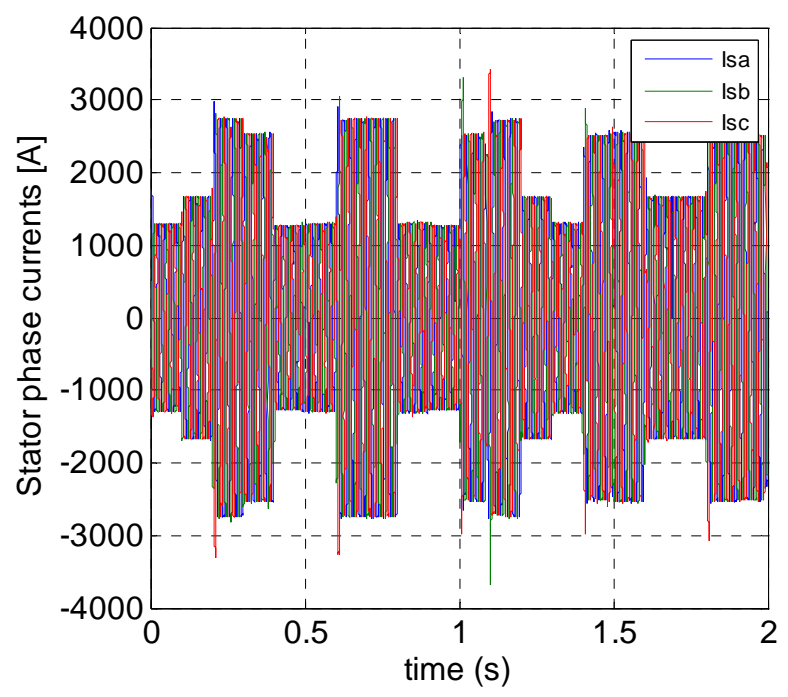

Figure 9. Stator phase currents with PWM

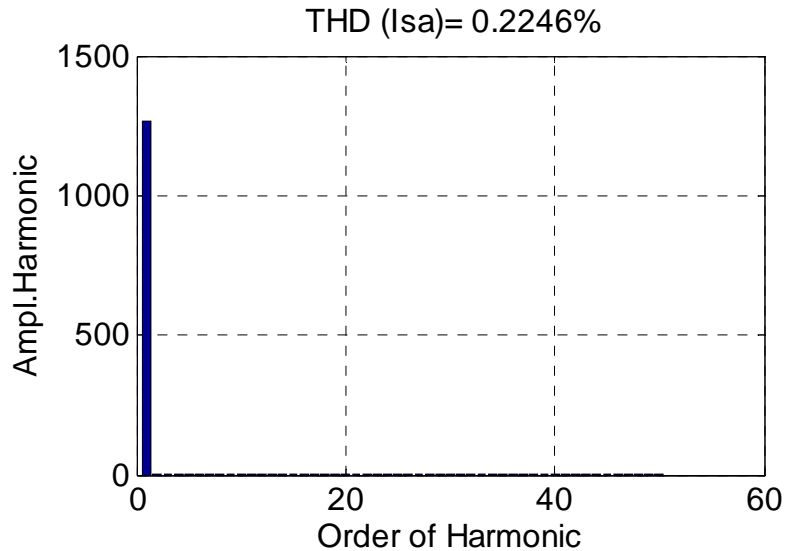

Figure 10. THD of current Isa with PWM

\section{SPACE VECTOR MODULATION (SVM)}

Modulation techniques different spatial vectors of the carrier on the basis of this manner, there is no separate modulators used for each of the three phases. Instead of them, the reference voltages are supplied by the voltage vector of the space and the output voltages of the inverter are considered space vectors [12]:

$$
V_{i}=\left\{\begin{array}{l}
\frac{2}{3} \\
0 i=0,7
\end{array} U_{d c} e^{\frac{j(i-1) \pi}{3}} i=1 . .6\right.
$$

There is a possible eight vectors output voltage, six active vectors $\mathrm{V}_{1}-\mathrm{V}_{6}$, and two zero vectors $\mathrm{V}_{0}, \mathrm{~V}_{7}$ figure 10 . The reference voltage vector is performed by sequentially switching the active and zero vectors.

In Figure 10 shows voltage vector reference voltage $V_{c}$ and eight vectors, which corresponds to the possible states of the inverter. The six active vectors divide a plane for the six sectors $1-6$. In the sector of each of the voltage reference vector $V_{c}$ is obtained by switching on, for a suitable time, two adjacent vectors. Shown in Figure 10 reference vector $V_{c}$ can be implemented by switching vectors $V_{1}, V_{2}$ and zero vectors $V_{0}$, $\mathrm{V}_{7}[13],[14]$. 


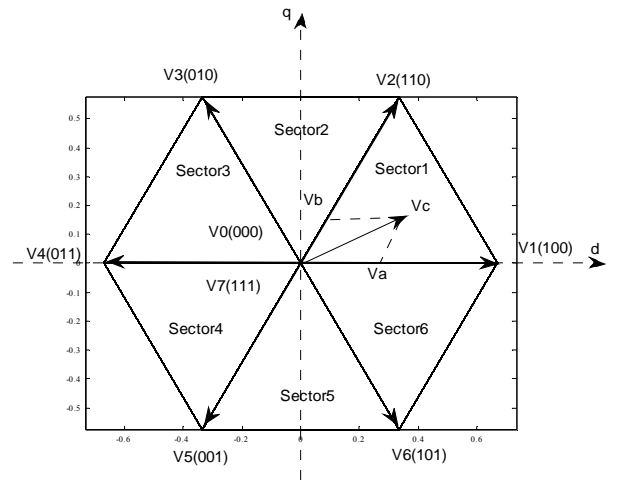

Figure 10. Principle of the space vector modulation

The reference voltage vector $V_{c}$ is sampled with the fixed clock frequency $f_{s}=1 / T_{s}$, and next a sampled value $V_{c}\left(T_{s}\right)$ is used for calculation of times $t_{1}, t_{2}, t_{0}$ and $t_{7}$. The signal flow in space vector modulator is shown in Figure 11 .

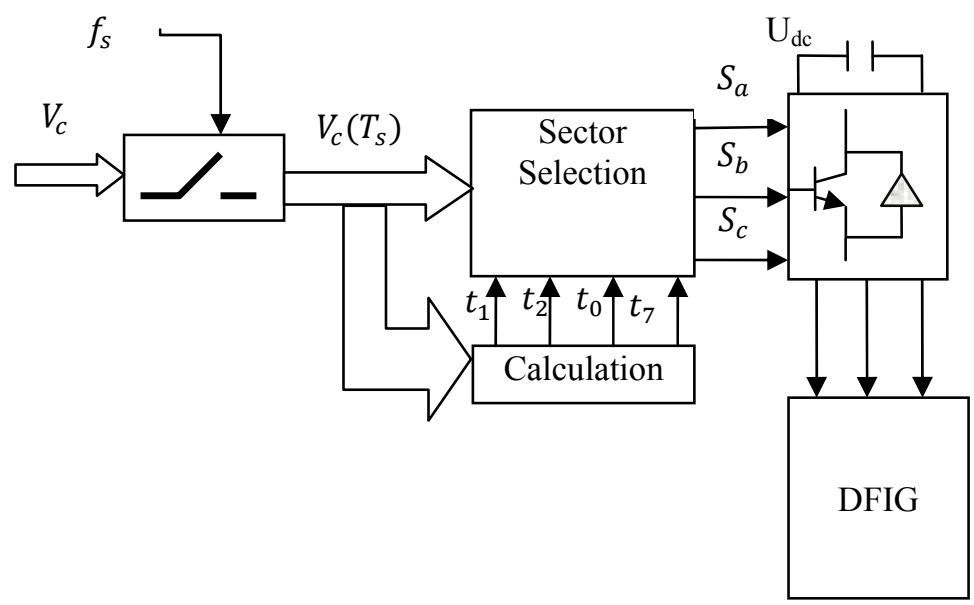

Figure 11. Block scheme of the space vector modulator

\section{THE SIMULATION RESULTS OF THE INDIRECT CONTROL WITH SVM}

The rotor of the DFIG is powered by a three-phase balanced system, and by a voltage to SVM inverters. To simulate the behavior of the DFIG, we opted for the MATLAB / Simulink software, the simulation results are given by the following figures 


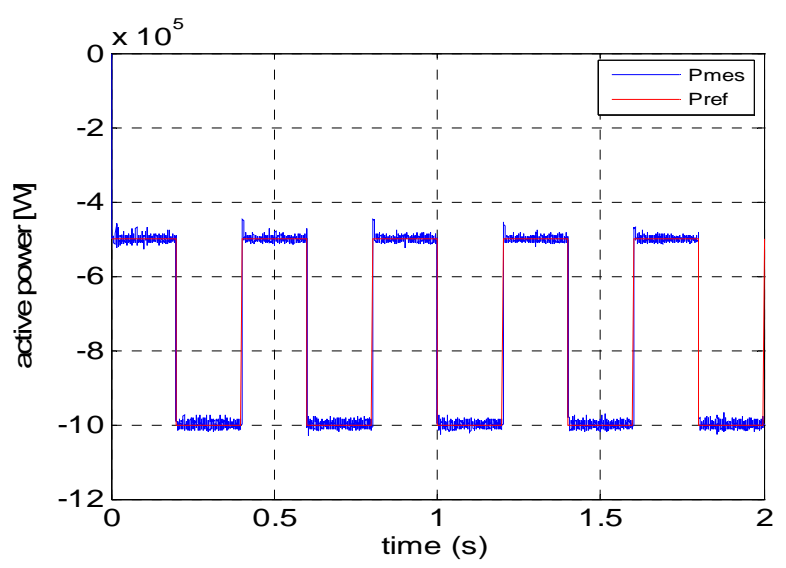

Figure 12. Electrical active power produced with SVM

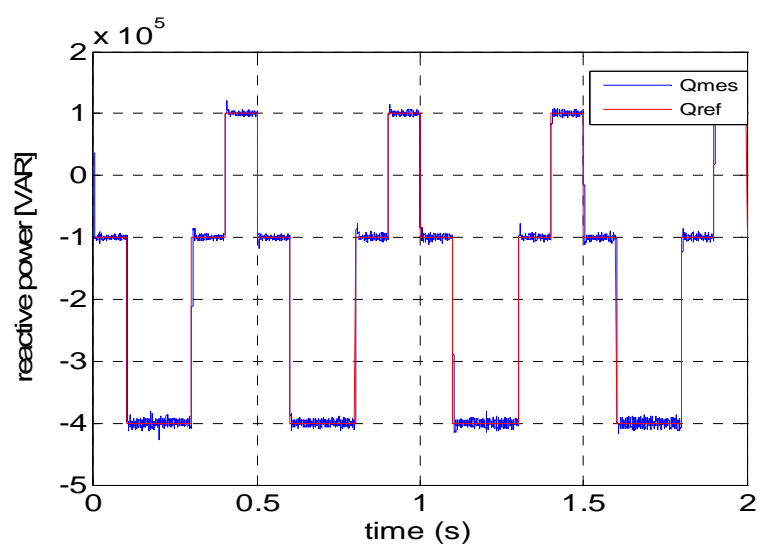

Figure 13. Electrical reactive power produced with SVM

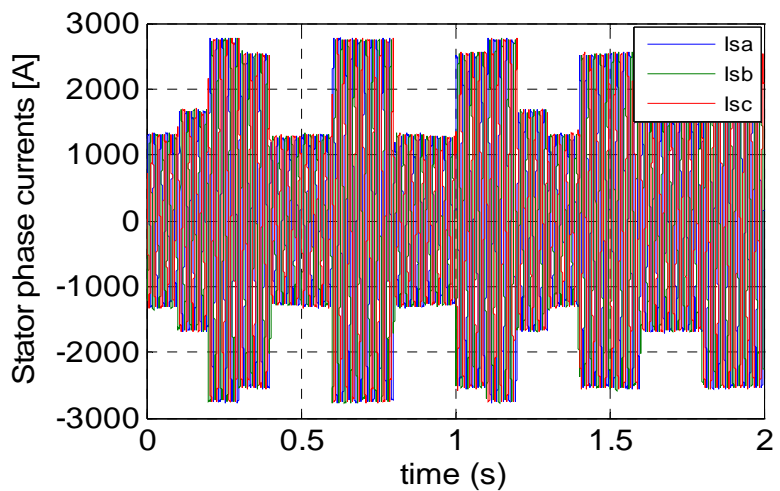

Figure 14. Stator phase currents with SVM 


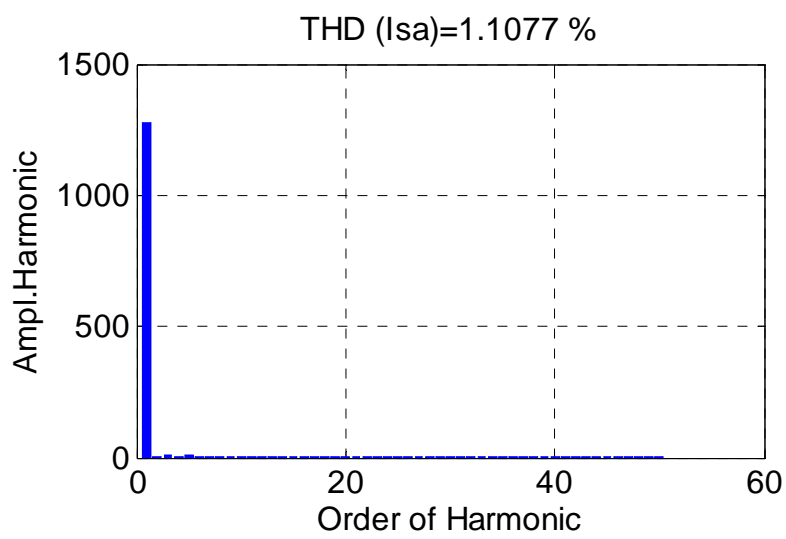

Figure 11. THD of current Isa with SVM

\section{CONCLUSION}

In our work, we have established the model the machine with its electric equations in axis linked to the d-q synchronous system. We have also developed the method of vector control power of the machine to know the order and dedicated to the study of the art of the power of indirect control to achieve the DC-AC conversion using two voltage levels with technical PWM controller Pulse Width Modulation and SVM Modulation Vector Space. Indeed we have seen that the control indirectly allows us, together with the closure powers, to have an efficient system and robust. It is certainly more complex to work, but will have an operation optimal system of electric generation minimizing potential problems related to changes in machine parameters and the wind system.

\section{APPENDIX A}

- $\quad$ Nominal Power $=1.5(\mathrm{Mw})$

- $\quad$ Stator Per Phase Resistance $=0.012(\Omega)$

- Rotor Per Phase Resistance=0.021 $(\Omega)$

- $\quad$ Stator Leakage Inductance $=2.0372 .10^{-004}(\mathrm{H})$

- $\quad$ Rotor Leakage Inductance $=1.7507 .10^{-004}(\mathrm{H})$

- Magnetizing Inductance $=0.0135(\mathrm{H})$

- Number Of Poles Pairs=2

- Moment Of Inertia $=1000\left(\mathrm{Kg} . \mathrm{M}^{2}\right)$

- $\quad$ Friction Coefficient $=0.0024$

\section{REFERENCES}

[1] Z. Lubosny, "Wind Turbine Operation in Electric Power Systems“, Berlin, Germany: Springer, 2003.

[2] S. Heier, "Gid Integration of Wind Energy Conversion Systems". England: John Wiley \& Sons, 1998.

[3] J. Usaola, P. Ledesma, J.M. Rodriguez, J.L. Fernadez, D. Beato, R. Iturbe, J.R. Wihelmi, "Transient stability studies in grids with great wind power penetration. Modeling issues and operation requirements", Proceedings of the IEEE PES Transmission and Distribution Conference and Exposition, September 7-12, 2003, Dallas (USA).

[4] S.El Aimani, "Modélisation De Différentes Technologies D’éoliennes Intégrées Dans Un Réseau De Moyenne Tension“.

[5] F. Poitiers, "Etude Et Commande De Génératrices Asynchrones Pour L'utilisation De L'énergie Eolienne“, 2003.

[6] A. Boyette, "Contrôle-commande d'un générateur asynchrone a double alimentation avec système de stockage pour la production éolienne", thèse 2006.

[7] T. Ghennam, E.M. Berkouk, B. Francois, "Modeling and Control of a Doubly Fed Induction Generator Based Wind Conversion System", International conference on power engineering, energy and electrical drives (POWERENG 2009), Lisbon, Portugal, 18-20 Mach 2009.

[8] A. Mehdary, 'Étude d'une chaine de conversion d'énergie éolienne à base d'une aéroturbine", 6 émes Journées des doctorants, Laboratoire des sciences de l'information et des systèmes LSIS, université de St Jérôme, Marseille,2009. 
[9] H. Tamrabet, "robustesse d'un contrôle vectoriel de structure Minimale d'une MAS“, 'magister memory option Electronic power univ Batna supported on 20/05/2006.

[10] B.K. Bose, "Modern Power Electronics and AC drives", Prentice-Hall, 2002.

[11] J. Holtz, "Pulsewidth modulation for electronic power conversion",Proceedings of the IEEE, Vol. 82, Issue: 8, Aug. 1994, pp.1194-1214.

[12] Marcin Z. "Space Vector Modulated - Direct Torque Controlled (DTC - SVM) Inverter - Fed Induction Motor Drive“, Warsaw - Poland, 2005.

[13] H. Djeghloud, "Filtrage Activf de Puissance", thèse 2007.

[14] L. Moussaoui, "Etude De La Commande De L’Ensemble Machine Asynchrone-Onduleur à Source De Courant", thèse 2007.

\section{BIOGRAPHIES OF AUTHORS}
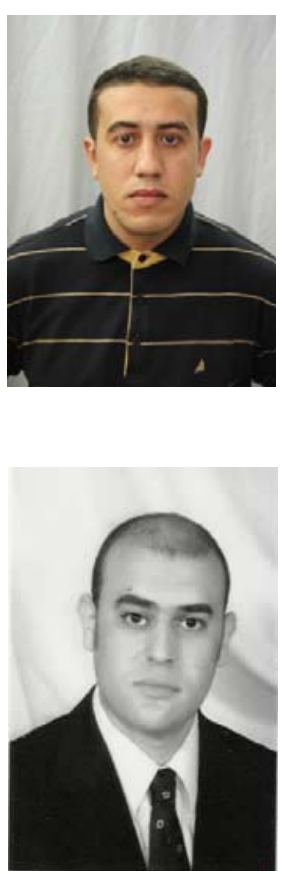

Naim Cherfia was born in Constantine, Algeria in 1982. He received the Engineer of state in electrotechnic, Option: Electric Machines, from Mentouri Constantine 1 University in 2007, and magisterial degrees in 2010 option: Modeling and control of electric machines, from Mentouri Constantine 1 University in 2010. Now he is PhD student and researcher's member in LGEC Research Laboratory, Department of Electrical Engineering, Constantine 1 University, His research interests include modern theory application control, electric machines drives, and power electronics.

Djallel Kerdoun received the B. Sc. Degree and M. Sc. degree in electrical drive and automation of industrial and technological complexes from the Technical University, Institute of Energy of Moscow, Russia, in 1995 and 1997, respectively. And he received the Ph.D. degree in electrical engineering from the Technical University, Institute of Energy of Moscow, Russia, in 2001 for his work on Asynchronous Electric Drive of Spherical Drum-Type Mills with use of Voltage Regulator.

Since 2004, he has been with the Department of Electrical Engineering, The University of Constantine1, Constantine, Algeria, first as a Research Assistant, then as a Lecturer in power electronic systems, with the Power electronics, Machines, and Control Group.

His research interests include Solid State Drives, Power Converters, Electrical Machines, and Wind and Photovoltaic Power Generation. 